\title{
1 Intrahost speciations and host switches shaped the evolution of herpesviruses
}

\author{
$4 \quad$ ANDERSON F. BRITO ${ }^{1 *}$; JOHN W. PINNEY ${ }^{1 *}$ \\ 5 1. Department of Life Sciences, Imperial College London, South Kensington Campus. \\ 8 * Corresponding authors: Anderson F. Brito - andersonfbrito@gmail.com

\section{ABSTRACT}

12 Cospeciation has been suggested to be the main force driving the evolution of

13 herpesviruses, with viral species co-diverging with their hosts along more than 400 million

14 years of evolutionary history. Recent studies, however, have been challenging this

15 assumption, showing that other co-phylogenetic events, such as intrahost speciations and

16 host switches play a central role on their evolution. Most of these studies, however, were

17 performed with undated phylogenies, which may underestimate or overestimate the

18 frequency of certain events. In this study we performed co-phylogenetic analyses using

19 time-calibrated trees of herpesviruses and their hosts. This approach allowed us to (i) infer

20 co-phylogenetic events over time, and (ii) integrate crucial information about continental

21 drift and host biogeography to better understand virus-host evolution. We observed that

22 cospeciations were in fact relatively rare events, taking place mostly after the Late

23 Cretaceous ( 100 Millions of years ago). Host switches were particularly common among

24 alphaherpesviruses, where at least 10 transfers were detected. Among beta- and

25 gammaherpesviruses, transfers were less frequent, with intrahost speciations followed by

26 losses playing more prominent roles, especially from the Early Jurassic to the Early

27 Cretaceous, when those viral lineages underwent several intrahost speciations. Our study

28 reinforces the understanding that cospeciations are uncommon events in herpesvirus 
bioRxiv preprint doi: https://doi.org/10.1101/418111; this version posted May 17, 2020. The copyright holder for this preprint (which was not certified by peer review) is the author/funder, who has granted bioRxiv a license to display the preprint in perpetuity. It is made available under aCC-BY-NC-ND 4.0 International license.

29 evolution. More than topological incongruences, mismatches in divergence times were the

30 main disagreements between host and viral phylogenies. In most cases, host switches

31 could not explain such disparities, highlighting the important role of losses and intrahost

32 speciations in the evolution of herpesviruses.

33

34 Keywords: tree reconciliation; herpesvirus; phylogenetics; host transfers; virus-host evolution

35

\section{INTRODUCTION}

Herpesviridae is a diverse family of large double-stranded DNA viruses subdivided in 38 three subfamilies - Alpha-, Beta-, and Gammaherpesvirinae -, which infect different 39 groups of vertebrates, including birds, mammals and reptiles (Davison et al. 2009). The 40 evolutionary history of herpesviruses (HVs) dates from the Early Devonian, around at least 41400 Millions of years ago (Mya) (McGeoch et al. 2006). Up to recent years, HVs were 42 considered to be species-specific, and to have evolved alongside their hosts mainly by 43 cospeciation (McGeoch et al. 1995; Davison 2002; Jackson 2005; McGeoch et al. 2006),

44 an event that implies concurrent and interdependent splits of host and viral lineages over 45 time (de Vienne et al. 2013). As more information about the divergence timing of host and 46 viral species became available, the predominance of cospeciation as the main mechanism 47 of $\mathrm{HV}$ evolution started to be challenged, especially due to mismatches between the 48 divergence times of hosts and viruses, which evoked alternative hypothesis to explain HV 49 evolution, such as host switches (transfers) (Davison 2002; Escalera-Zamudio et al. 2016).

50 Transfers take place when viruses succeed in infecting a new host still unexplored by 51 their ancestors (de Vienne et al. 2013). Recent studies have been suggesting that host 52 switches are probably more frequent than previously thought (Escalera-Zamudio et al.

53 2016; Geoghegan et al. 2017), but detecting host switches can be difficult, as extinctions 
54 of viruses transmitted to new hosts may occur frequently (Geoghegan et al. 2017).

55 Duplication of viral lineages (intrahost speciation) is another evolutionary process playing

56 an important role on host-pathogen evolution (de Vienne et al. 2013). By means of

57 intrahost speciations, multiple species of viruses can explore a single host species,

58 especially when new lineages occupy distinct biological niches (tissues) within the hosts

59 (Davison 2002). Finally, another event playing a key role in host-virus evolution is the loss

60 of viral lineages, events that in a co-phylogenetic context can mean: (i) symbiotic extinction

61 (Lovisolo et al. 2003); (ii) sorting events (Johnson et al. 2003); or even (iii)

62 rare/undiscovered species, as a result of undersampling (Page and Charleston 1998).

63 The aforementioned mechanisms can be inferred using co-phylogenetic analyses,

64 such as tree reconciliations, which help us understand the relationship between hosts and

65 parasites over time (Page and Charleston 1998). To do that, such methods identify

66 differences and similarities between the topologies of host and parasite trees, where

67 congruence may indicate points of co-divergence (cospeciation), while incongruences my

68 imply host switches or intrahost speciations followed by losses (de Vienne et al. 2013).

69 Topological congruence, however, not always is caused by cospeciation events: similar

70 topologies of host and parasite phylogenies can happen by chance, as a result of repeated

71 host switches (de Vienne et al. 2013). To better understand the intricate evolutionary

72 processes of HVs, co-phylogenetic analyses can be applied to elucidate the pathways

73 taken by viruses while their hosts and the environment evolve. By integrating time-

74 calibrated phylogenies and historical biogeographical information, in this study we present

75 detailed scenarios unravelling the evolution of herpesviruses with their hosts, providing

76 answers to the following questions: (i) What are the main co-phylogenetic events shaping

77 HV evolution?; (ii) How have herpesviruses achieved their broad host range?; (iii) Have

78 the three HV subfamilies evolved following similar strategies? 
bioRxiv preprint doi: https://doi.org/10.1101/418111; this version posted May 17,2020 . The copyright holder for this preprint (which was

not certified by peer review) is the author/funder, who has granted bioRxiv a license to display the preprint in perpetuity. It is made available under aCC-BY-NC-ND 4.0 International license.

80 RESULTS

81

82 Phylogenetic analysis

83 Herpesvirus evolutionary history is older than that of their extant hosts (McGeoch et al.

84 2006). The MRCA (Most Recent Common Ancestors) of all hosts date back between 352

85 and 307 Mya, while the MRCA of all HV subfamilies existed at least between 416 and 373

86 Mya. As evidenced by the tanglegram in Figure 1, despite the apparent congruence of

87 some clades in both phylogenies, topological disagreements are common for most virus-

88 host pairs, as highlighted by the overcrossing connections between the trees. 


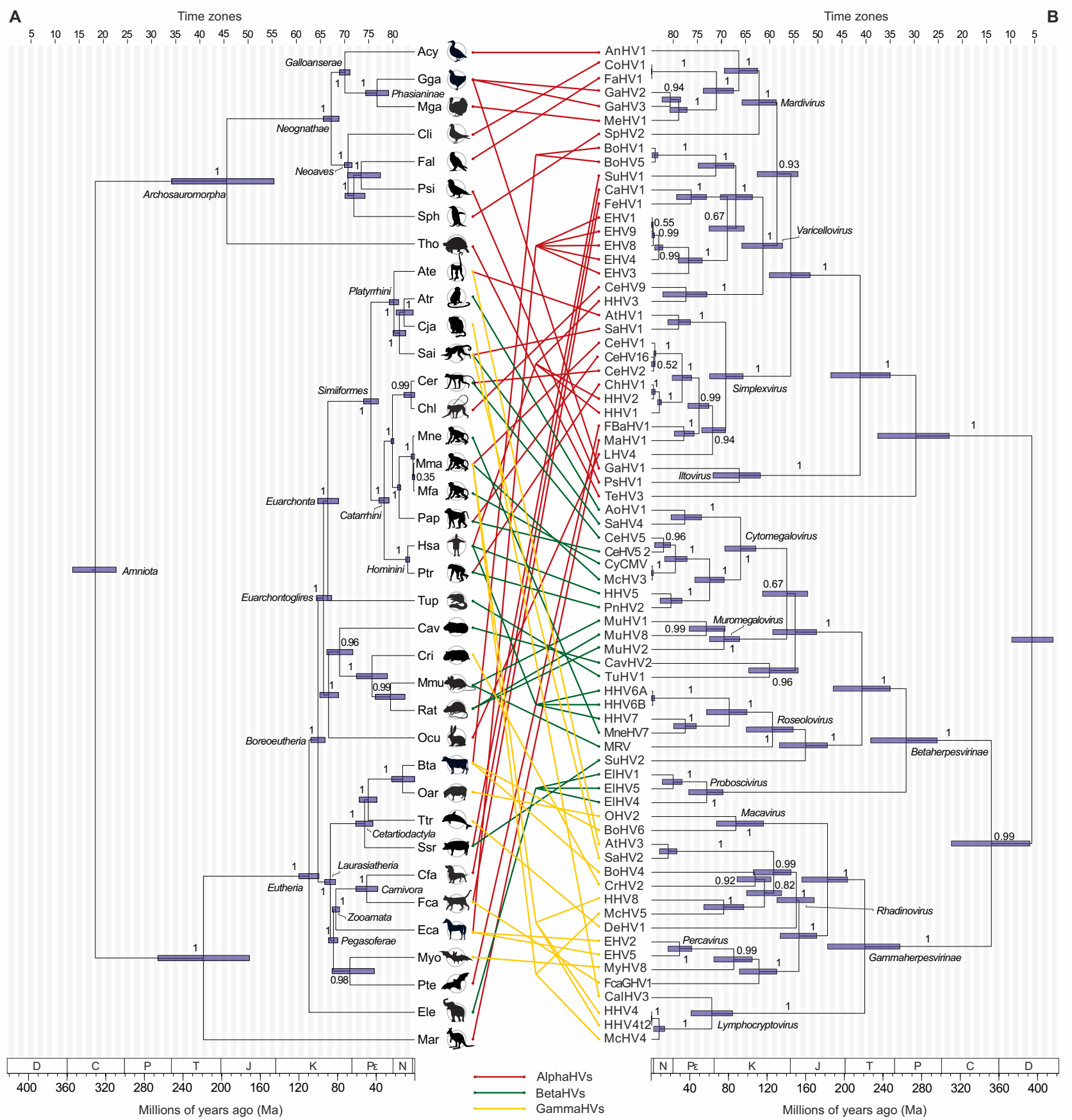

90 Figure 1. Host-virus tanglegram. Viruses (right) are connected to their hosts (left) with lines 91 whose colours denote the three herpesviral subfamilies: Alpha- (red); Beta- (green) and 92 Gammaherpesvirinae (yellow). Node height HPD intervals of hosts and viruses are shown as bars, 93 labels are provided for some taxonomic groups, and all nodes are assigned with posterior 94 probabilities. All internal nodes in the host tree were time-calibrated with priors. In the viral tree, 95 priors were assigned to only two nodes (the root node and HHV1-HHV2 MRCA), while the others 96 had their date ranges estimated from sequence data. Both trees are divided in time zones of 5 $97 \mathrm{Myr}$, as shown by the scale at the top, and some node HPD intervals span more than one time 98 zone. The geologic time scale is set according to (Gradstein et al. 2012), where $D=$ Devonian 99 period; $\mathrm{C}=$ Carboniferous; $\mathrm{P}=$ Permian; $\mathrm{T}=$ Triassic; $\mathrm{J}=$ Jurassic; $\mathrm{K}=$ Cretaceous; $\mathrm{P} \varepsilon=$ 100 Paleogene; $\mathrm{N}=$ Neogene; and ${ }^{*}=$ Quaternary period. Host acronyms are defined as follows: Acy =

101 Anser cygnoides; Ate = Ateles sp.; Atr = Aotus trivirgatus; $\mathrm{Bta}=$ Bos taurus $;$ Cav = Cavia porcellus;

$102 \mathrm{Cer}=$ Cercopithecus aethiops; $\mathrm{Cfa}=$ Canis lupus familiaris; $\mathrm{Chl}=$ Erythrocebus patas; $\mathrm{Cja}=$ 
103 Callithrix jacchus; Cli = Columba livia; Cri = Cricetidae; Eca = Equus caballus; Ele = Elephas 104 maximus; Fal = Falco mexicanus; Fca = Felis catus; $\mathrm{Gga}=$ Gallus gallus; $\mathrm{Hsa}=$ Homo sapiens;

105 Mar = Macropodidae; Mfa = Macaca fascicularis; Mga = Meleagris gallopavo; Mma = Macaca

106 mulatta; Mmu = Mus musculus; Mne = Macaca nemestrina; Myo = Myotis velifer, Oar = Ovis aries;

107 Ocu = Oryctolagus cuniculus; Pap = Papio sp.; Psi = Amazona oratrix; Pte = Pteropus sp.; Ptr =

108 Pan troglodytes; Rat = Rattus sp.; Sai = Saimiri sp.; Sph = Spheniscus sp.; Ssr = Sus scrofa; Tho

109 = Testudo horsfieldii; Ttr = Tursiops truncatus; and Tup = Tupaiidae. For more details on host and

110 viral taxonomy, accession numbers, and TaxID can be found in S1 Table.

112 Cost regimes

113 The co-phylogenetic analysis of 72 herpesviral species and their respective 37 hosts has

114 revealed different possible scenarios to explain their evolution, according to distinct event

115 costs. We tested 256 cost regimes, which favoured or penalized events differently (see

116 supplementary tables S2-S4). Since the association of internal nodes in viral and host

117 trees was constrained by their time zone ranges, the total number of possible solutions

118 was limited, with many cost regimes resulting in similar solutions, which differed mostly in

119 terms of the time zones where the inferred events probably took place. As shown in Figure

120 2, except for AlphaHVs (Figure 2A), the number of possible solutions (i.e. the number of

121 events inferred for each event type, in distinct cost regimes) was very restricted in

122 reconciliations involving BetaHVs and GammaHV, with both showing two main scenarios

123 (Figure 2B and C): one with high numbers of Intrahost Speciations (IS) and Losses (LO),

124 resulting in less likely solutions; and another one where such events were inferred at much

125 lower numbers, mostly matching the median values (grey horizontal bars). For AlphaHVs,

126 such fluctuation between high and low numbers of IS and LO was also observed, but more

127 continuously distributed at both extremes. 


\section{8}

\section{9}

\section{0}
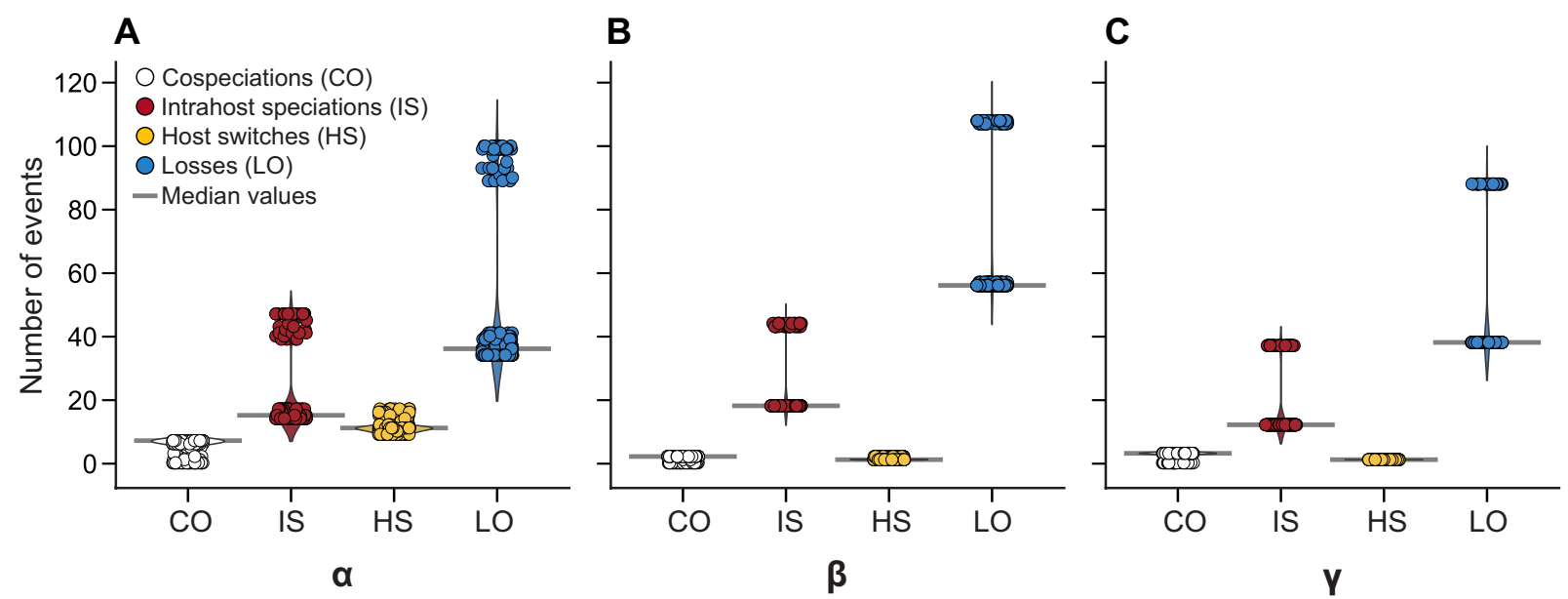

Figure 2. Co-phylogenetic events inferred in reconciliations between virus and host trees. A total of 256 distinct cost regimes were explored, resulting in distinct, but relatively similar scenarios explaining the disagreements between viral and host evolutionary histories. The main differences among the inferred scenarios concerned the number of Intrahost Speciations (IS, red) and Losses (LO, blue), two closely associated events. The panels show the number of inferred events under distinct cost regimes, in virus-host tree reconciliations involving A) AlphaHVs, B) BetaHVs and C) GammaHvs. Based on the median number of events for each event type (grey bars), an optimal cost regime was selected.

For each subfamily, a single cost regime was selected according to the following 139 order of criteria, it should: (1) reconstruct the median number of events for each event type

140 (as shown by grey bars on Figure 2); (2) ensure the highest possible support values for 141 reconstructed events, and; (3) output the lowest possible overall cost. As a result, an 142 optimal cost regime with the following relative costs was selected to explain the topological 143 disagreements between viral and host tree: Cospeciation $(\mathrm{CO})=0 ;$ Intrahost speciation $144(\mathrm{IS})=1$; Host Switch $(\mathrm{HS})=2$; and Loss $(\mathrm{LO})=0$. Since the reconciliations between HVs 145 from different subfamilies were analysed separately, it allowed us to examine the 146 predominance of each co-phylogenetic event across different HV genera (Figure 2), as 147 shown in the following sections.

149 Cospeciations over the last 100 millions of years

Cospeciations were only found after the Late Cretaceous ( 100 Mya), and have

151 shown to be a rare event among HVs (Figure 2 and 3). For alphaherpesviruses, seven 
bioRxiv preprint doi: https://doi.org/10.1101/418111; this version posted May 17, 2020. The copyright holder for this preprint (which was not certified by peer review) is the author/funder, who has granted bioRxiv a license to display the preprint in perpetuity. It is made available under aCC-BY-NC-ND 4.0 International license.

152 cospeciation events were reconstructed (Table 1), the oldest one assigned to the Late

153 Cretaceous ( 92-81 Mya), involving ancestors of Varicellovirus infecting Laurasiatheria

154 mammals (see Figure 4). This event was followed by at least other two cospeciations, one

155 at the split of ancestors of canines, felines and equines (Zooamata); and another at the

156 split of Carnivora ancestors. Among mardiviruses, ancestors of GaHV1 and PsHV1 (genus

157 Iltovirus) co-diverged with bird ancestors (Neognathae) around 78-94 Mya, similar to what

158 occurred for viruses infecting ancestors of chickens and turkeys (Phasianinae) around 36-

15926 Mya. Finally, among simplexviruses infecting Catarrhini (Old World Monkeys and

160 Apes), two cospeciations were found, one taking place most likely at the Oligocene ( 36-

16126 Mya); and the second at the Miocene ( 9-5 Mya), involving viruses infecting ancestors

162 of Humans and Chimpanzees (Hominini).

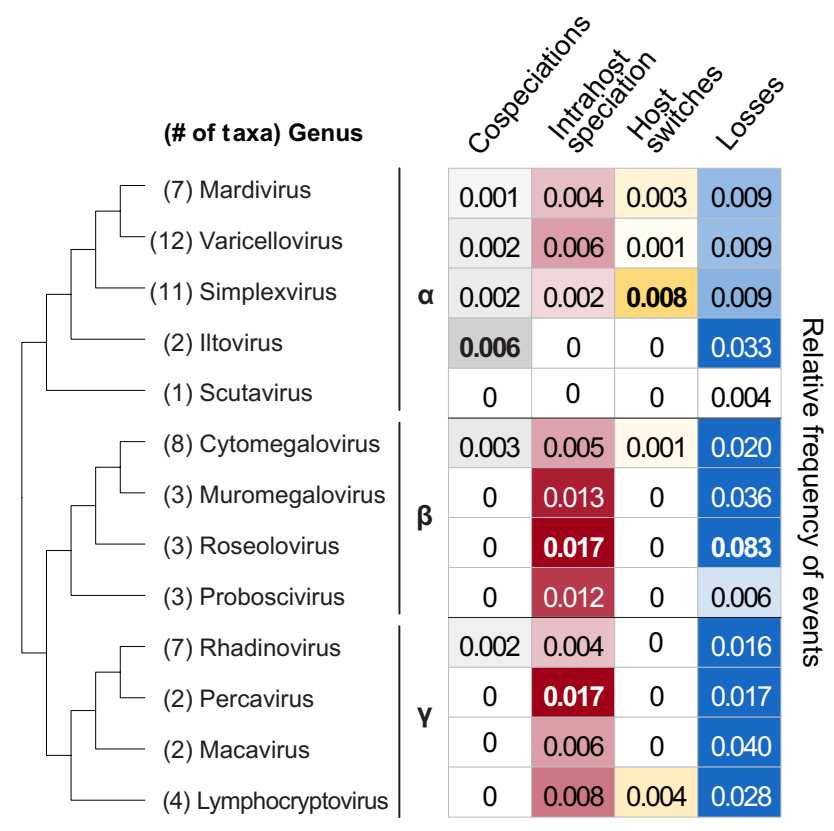

164 Figure 3. Relative frequency of co-phylogenetic events in distinct herpesviral genus,

165 considering the optimal cost regime. Values are normalized by the total number of taxa in each

166 genus, and their respective times to the MRCA. As highlighted, losses were the most frequent co-

167 phylogenetic events, followed by intrahost speciations. 


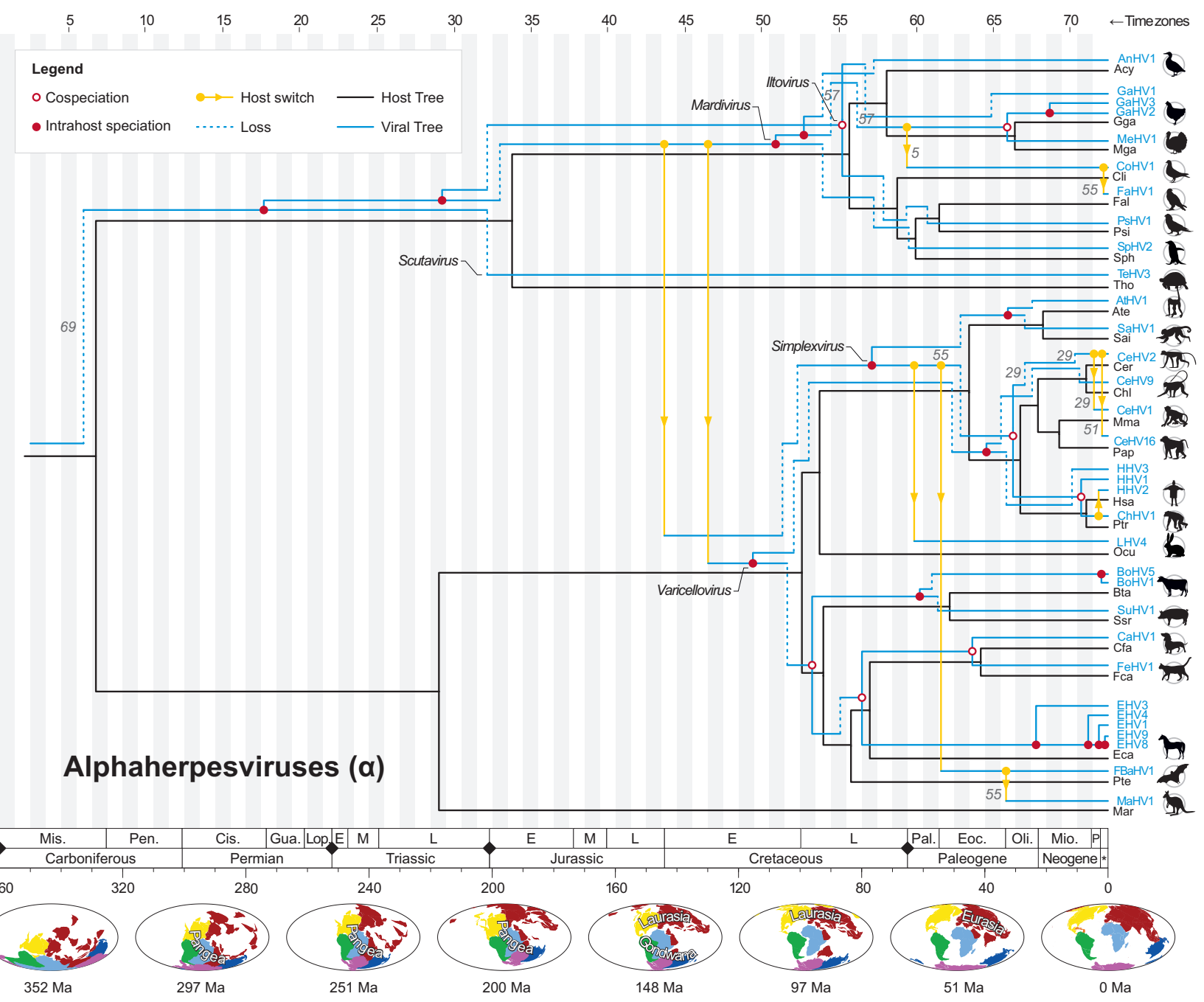

Figure 4. Tree reconciliation of Alphaherpesviruses and their hosts. In this representation, the host tree is shown in black, and the viral tree is shown in blue, vertically twisted, keeping its original topology and assigned time zones as shown in Figure 1. Co-phylogenetic events with

173 support values (\%) below 100 are shown. Along the time scale, black diamonds denote major 174 events of mass extinction, as described in (Raup 1993). The maps at the bottom show changes of 175 landmasses (continental drift) over time, and were retrieved from PBDB (Peters and McClennen 176 2015). Cis. = Cisuralian; $\mathrm{E}=$ Early; Eoc. = Eocene; Gua. = Guadalupian; L = Late; Lop. = 177 Lopingian; $\mathrm{M}=$ Middle; Mio. = Miocene; Mis. = Mississippian; Oli. = Oligocene; $\mathrm{P}=$ Pliocene; Pal. = 178 Paleocene; Pen. = Pennsylvanian; and ${ }^{*}=$ Quaternary . 
179 Table 1. Overall statistics of co-phylogenetic events inferred under the optimal cost regime 180 used for virus-host tree reconciliations. The number of inferred events per HV subfamily ( $\alpha, \beta$ 181 and y) match the median values in Figure 1. Cospeciation $=(C O)$; Intrahost speciation $=($ IS $)$; Host

182 Switch $=(\mathrm{HS})$; and Loss $=($ LO $)$.

\begin{tabular}{cccccc}
\hline \multirow{2}{*}{ Subfamily } & \multicolumn{4}{c}{ Number of inferred events } & Overall \\
\cline { 2 - 5 } & CO & IS & HS & LO & cost \\
\hline$\alpha$ & 7 & 15 & 10 & 36 & 35 \\
$\beta$ & 2 & 18 & 1 & 56 & 20 \\
Y & 3 & 12 & 1 & 38 & 14 \\
\hline
\end{tabular}

In Betaherpesviruses, only two cospeciations were reported, both along the lineage

185 of cytomegaloviruses infecting ancestors of Cercopithecine (macaques and baboons)

186 (Figure 5): the first one at the Paleogene-Neogene boundary ( 24-21 Mya); and the

187 second one around 0.8 Mya, the most recent cospeciation found in this study, involving

188 ancestors of CyCMV and McHV3, at the split between Macaca fascicularis (Mfa) and M.

189 mulatta (Mma).

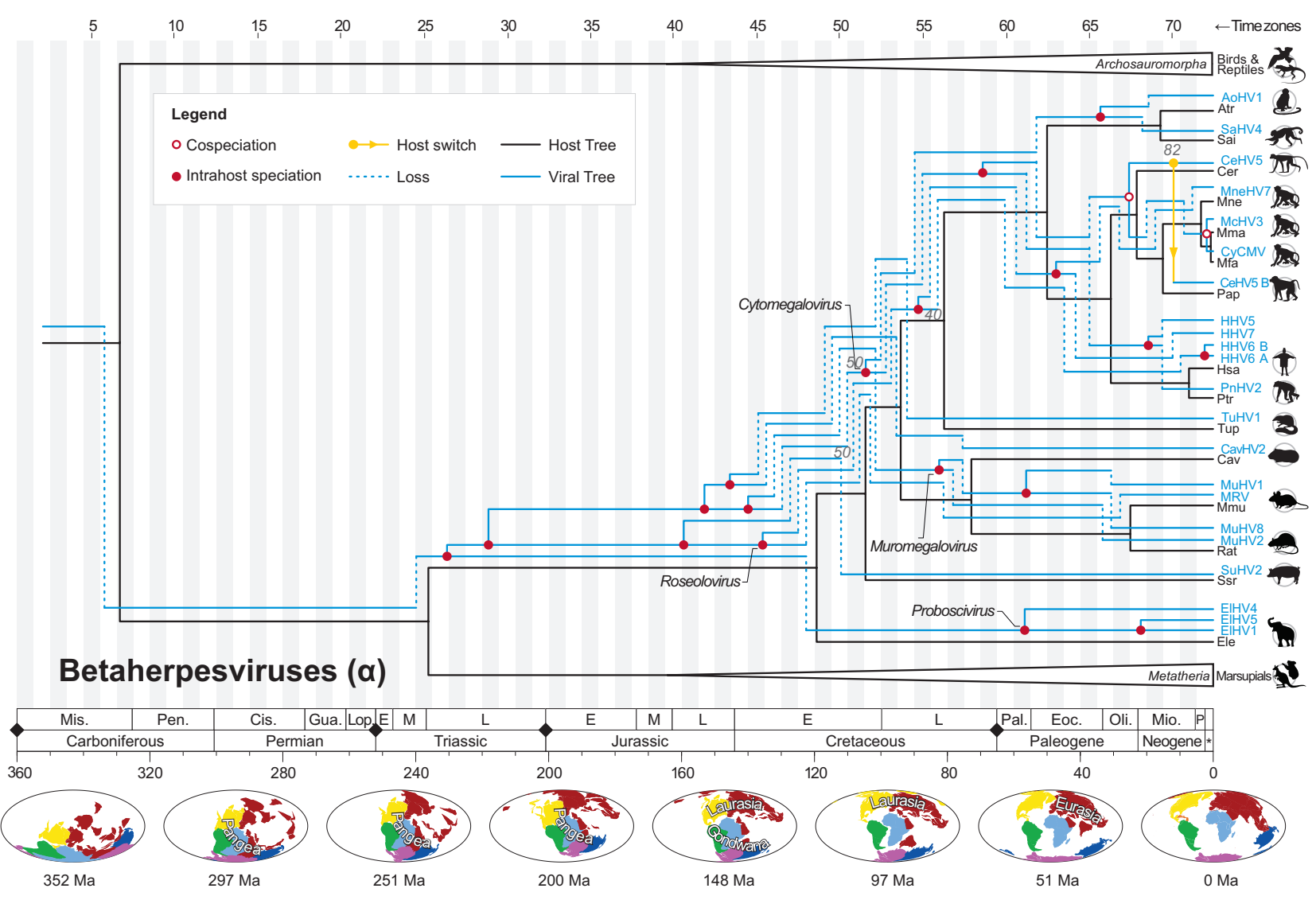

191 Figure 5. Tree reconciliation of Betaherpesviruses and their hosts. 
Among Gammaherpesviruses, three cospeciations were found in different periods

194 (Figure 6). The earliest event involved Macavirus ancestors, and took place at the split

195 between Laurasiatheria and Euarchontoglires (Early Cretaceous, 99 Mya). Following this

196 event, HVs infecting ancestors of bats, equines and felines (Pegasoferae) co-diverged

197 with their hosts at the Late Cretaceous ( 88-79 Mya); and finally, at the Paleogene-

198 Neogene boundary ( 25-16 Mya), Rhadinovirus ancestors co-diverged with New World

199 Monkeys (Platyrrhini).

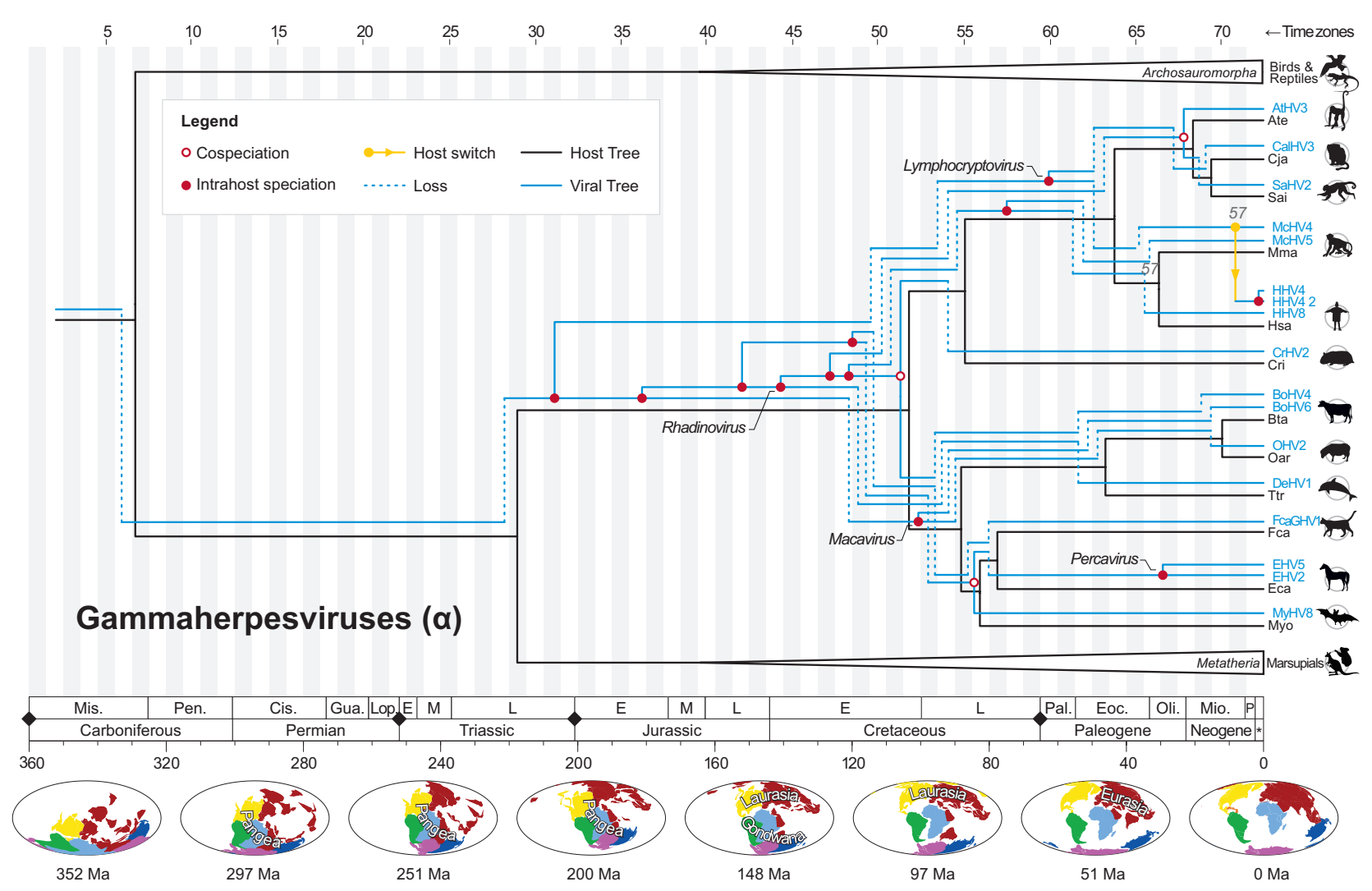

Figure 6. Tree reconciliation of Gammaherpesviruses and their hosts. 
203 Intrahost speciations: duplications of viral lineages

Intrahost speciations (also known as duplications) occur when a parasite diverges

205 and both lineages remain within the same host species, and represent alternative modes

206 of evolution that explain mismatches between divergence times of viruses and hosts (de

207 Vienne et al. 2013). Intrahost speciation was the second most frequent co-phylogenetic

208 event in the evolution of HVs (Figure 2 and 3). Along the evolution of AlphaHVs, such

209 events were particularly common after the Early Cretaceous. During the Permian and

210 Triassic periods, when AlphaHVs infected ancestors of birds and reptiles

211 (Archosauromorpha), two important intrahost speciations gave rise to ancestors of the

212 main genera of Alphaherpesvirinae (Figure 4). Later in their evolution, along the

213 Paleogene and Neogene, these viruses underwent a process of diversification that gave

214 rise to multiple species sharing common hosts, as observed for Gallid (GaHV2, 3); Equid

215 (EHV1, 3, 4, 8, 9); and Bovine alphaherpesviruses (BHV1, 5). Differently from these recent

216 duplications, older duplication events were always followed by losses, which may explain,

217 for example, the apparent lack of scutaviruses infecting birds, or mardiviruses and

218 iltoviruses infecting reptiles. The evolutionary histories of BetaHVs and GammaHVs are

219 also largely characterized by intrahost speciations (Figure $2 \mathrm{~B}$ and $2 \mathrm{C}$ ). As a consequence

220 of early intrahost speciations, ancestors of BetaHV and GammaHV co-existed infecting

221 early placental mammals from the Late Triassic to the Early Cretaceous, period when such

222 viral lineages experienced extensive diversification (Figure 5 and Figure 6).

223

224 Losses: extinctions, sorting events and undiscovered herpesviruses

Among the four co-phylogenetic events, losses were the most common (Figure 2 and

226 3). Remarkably, considering all HV subfamilies, more than half of the losses (nearly $54 \%$ )

227 were assigned to the Cretaceous period ( 145-66 Mya). As previously mentioned, losses 
228 are usually preceded by intrahost speciations, and highlight host clades that lack viruses

229 from certain lineages. At this point it is essential to emphasize that in the context of host-

230 parasite tree reconciliations, losses can be interpreted in at least three distinct ways: (1) as

231 lineage sorting events ('missing the boat'), when a parasite fails to disperse to one of the

232 new host species after their speciation (Johnson et al. 2003); (2) as undiscovered or rare

233 parasites (low sampling) (Page and Charleston 1998); or (3) as genuine events of parasite

234 extinctions (Lovisolo et al. 2003). In the latter scenario, if extinctions explain the absence

235 of viruses infecting certain host clades, it is important to consider that points of losses in

236 reconciliations do not reflect the exact time of the extinctions, but rather highlight a point

237 from which such events could have happened at any subsequent time.

238 Throughout the evolution of herpesviruses, in Figure 4, Figure 5, and Figure 6, viral

239 losses are depicted as dashed lines pointing towards the opposite direction the losses are

240 assigned to. In the evolution of AlphaHVs, for example, the oldest loss dates from the

241 Carboniferous period, before the split between sauropsids (bird/reptile ancestors) and

242 synapsids (mammal ancestors) (Figure 4). This loss was inferred due to the potential lack

243 of a basal group of AlphaHVs infecting synapsids in that time. Most losses of AlphaHVs

244 were assigned to periods after the Early Cretaceous, along the earliest events of

245 diversification of modern birds and mammals. Except for Scutavirus, a genus here

246 represented by a single species (TeHV3), all genera of Alphaherpesvirinae show extensive

247 losses between 110 and 70 Mya. Proportionally, losses were the most common events in

248 the evolution of the genus Iltovirus (Figure 3), an old clade of HVs infecting distantly

249 related avian families: Psittacidae and Phasianidae. Another context where losses played

250 a central role was during the evolution of varicello- and simplexviruses infecting

251 Euarchontoglires (a group that includes rabbits and primates). The evolution of these 
252 viruses alongside their hosts could only be explained by means of multiple losses,

253 especially from 90 Mya onwards, where at least 12 losses were observed.

Along the evolution of Beta- and Gammaherpesviruses losses were predominant.

255 Among the BetaHV genera, Roseolovirus has shown the highest level of losses (Figure 3).

256 Ancestors of these viruses originated most likely in the Early Cretaceous ( 146-119 Mya),

257 and across their evolution they were either lost in most host groups or may still exist as

258 rare/undiscovered viruses. In GammaHVs, the genus Macavirus showed the second

259 highest relative frequency of losses. Viruses in this taxonomic group are known to infect

260 Cetartiodactyla hosts, mostly ruminants and swine (Ehlers et al. 2008). Since the MRCAs

261 of these viruses and their Laurasiatheria hosts existed around 87 Mya (Late Cretaceous),

262 in case they were not extinct, macaviruses infecting Pegasoferae (felines, canines, 263 equines and bats) may still exist in nature.

265 Host switches

Host switches (transfers) take place when parasites succeed on infecting new hosts

267 not yet explored by their ancestors (de Vienne et al. 2013). In all scenarios (cost regimes)

268 investigated, host switches were invoked to explain herpesvirus-host evolution. Based on

269 the optimal cost regime adopted in our analyses (Table 1), at least 10 host switches were

270 reported for AlphaHVs. The oldest host switch took place when HVs from bird ancestors

271 (sauropsids) got transferred to placental mammals in the Early Cretaceous ( 144 Mya),

272 before the split between Mardivirus and Varicellovirus. Later ( 130 Mya), a second host

273 switch took place, giving rise to ancestors of all varicelloviruses, which currently are found

274 only in a wide range of mammalian hosts (Davison 2010) (Figure 4). Interestingly, other

275 than these two early transfers, all the remaining host switches of AlphaHVs were assigned

276 to periods after the Cretaceous-Paleogene boundary. In the Mardivirus lineage, viruses 
277 now infecting falconids and columbids (Neoaves) have likely originated after two host

278 transfers: one around the Paleocene ( 67 Mya) involving viruses from ancestors of

279 modern chicken and turkeys (Phasianinae); and a second one in more recent times, when

280 viruses infecting pigeons got transferred to falcons in the upper Pleistocene $(\sim 150$

281 thousands of years ago), the most recent transfer identified in this study.

282 Most notably, host switches were particularly common among simplexviruses, where

283 more than $2 / 3$ of the transfers in AlphaHVs were observed (Figure 3 ). In this genus, two

284 early transfers from primates gave rise to viruses now infecting Rabbits, Bats and

285 Marsupials: ancestors of Leporid alphaherpesvirus (LHV4) switched from primates to rabbits

286 around 76-52 Mya; and later, primate HVs switched to bats in the Eocene ( 54-41 Mya),

287 with descendants of these viruses later being transferred to marsupials in the Oligocene

288 ( 33 Mya), giving rise to the present-day Macropodid herpesvirus (MaHV1). The remaining

289 transfers involved the interchange of simplexviruses among Old World Monkeys and Apes

290 (Catarrhini) in the Pliocene. Ancestors of HVs now infecting monkeys of the genus Macaca

291 (Rhesus, infected by CeHV1), Papio (Baboons, infected by CeHV16), and Cercopithecus

292 (Guenons, infected by CeHV2) were likely transferred among these monkey species

293 between 3.3 and 2.1 Mya. The exact origin of their ancestors, and the polarity of the host

294 switches were not possible to be determined only by phylogenetic analysis, as multiple

295 possible scenarios have shown the same overall costs (see Figure 4). Finally, an important

296 Simplexvirus transfer took place between 3.6 and 0.1 Mya, when viruses infecting

297 Chimpanzees (genus Pan) were transferred to humans, giving rise to HHV2, as already

298 reported in a previous study (Wertheim et al. 2014).

299 In Beta- and GammaHVs, host switches were less prominent, with only one event

300 being assigned to each of these groups, both involving primate hosts. Among BetaHVs,

301 the species here named CeHV5-B (originally known as isolate OCOM4-52 (Blewett et al. 
302 2015)) originated in the Miocene ( 12 Mya) from viruses transferred from Guenon

303 ancestors (genus Cercopithecus). Finally, for GammaHVs our results provide a possible

304 explanation for the origins of HHV4 (Epstein-Barr Virus). Among lymphocryptoviruses,

305 McHV4, a Macacine gammaherpesvirus infecting Rhesus macaques (M. mulatta), is the

306 non-human HV more closely related to HHV4 (Figure 6). Ancestors of these viruses

307 infected either Apes (early hominids) or Old World Monkeys (early cercopithecids) around

30813.3 - 2.1 Mya, when these HVs switched hosts. For this particular event, the directionality

309 of the host transfer (hominids $\leftrightarrow$ cercopithecids) was not possible to be determined

310 because, given the tree topologies and node heights, both directions of transfer imply the

311 same overall cost. Despite that, other than host switch, no other co-phylogenetic event can

312 explain the existence of these viruses in macaques and humans.

\section{DISCUSSION}

To understand the presence of herpesviruses infecting distinct host groups, co-

317 phylogenetic analyses with time-calibrated trees can provide consistent explanation for the

318 dynamics of HVs evolution alongside their hosts. By using temporal data in tree

319 reconciliations, we could also incorporate information about geological and biogeographic

320 events that shaped life on Earth. A previous study placed the origin of herpesviruses in the

321 Devonian ( 400 Mya) (McGeoch and Gatherer 2005), a time reference used as one of the

322 priors to calibrate the herpesviral phylogeny in this study. Based on comparative structural

323 studies, it has been proposed that herpesviruses share a common ancestor with tailed

324 phages (Baker et al. 2005). This hypothesis may suggest an older origin for Herpesviridae,

325 however, the precise time range is not known, as these viruses do not produce identifiable

326 fossil evidences. In this way, to assign divergence times to herpesvirus trees, we made 
327 use of molecular clock estimates from previous theoretical studies (McGeoch and

328 Gatherer 2005; Wertheim et al. 2014). Despite the intrinsic uncertainties and limitations of

329 this method, we consider such estimates to be the most objective way so far available for

330 calibrating large DNA virus phylogenies. For this study, we calibrated the viral tree at only

331 two nodes (the deepest node, and a shallow node), letting the remaining intermediate

332 nodes free to have their dates estimated from sequence data. By setting constrains of

333 monophyly for well characterized viral and host taxonomic groups, we inferred robust

334 phylogenies with estimated ranges of divergence times, which allowed us to reconstruct, in

335 a temporal scale, the events underlying host-viral evolution since ancient periods.

For a long time, cospeciation has been considered to be the main evolutionary

337 mechanism driving the evolution of herpesviruses and their hosts (McGeoch et al. 1995;

338 Davison 2002; Jackson 2005; McGeoch et al. 2006). However, most previous studies

339 performed reconciliations using trees with few taxa, and without time scale, thus ignoring

340 mismatches between divergence times of host and viral ancestors. For cospeciations to be

341 accurately inferred, pathogen and host trees must not only show topological congruence,

342 but also correspondent divergence times (de Vienne et al. 2013). Thus, the absence of

343 temporal scale at internal nodes may overestimate the occurrence of certain events as a

344 result of chronologically inconsistent node pairings. In the present study we performed

345 reconciliation analyses using time-calibrated trees, which allowed us to observe that, due

346 to temporal incompatibilities, cospeciations were in fact rare events along the herpesviral

347 evolution, with other events playing more predominant roles.

348 After extensive phylogenetic characterization of herpesviruses, topological

349 disagreements between host and viral trees became evident, and since cospeciations

350 alone were no longer enough to explain the evolution of HVs, host transfers were initially

351 presumed to account for such incongruences (Ehlers et al. 2008; Escalera-Zamudio et al. 
bioRxiv preprint doi: https://doi.org/10.1101/418111; this version posted May 17, 2020. The copyright holder for this preprint (which was not certified by peer review) is the author/funder, who has granted bioRxiv a license to display the preprint in perpetuity. It is made available under aCC-BY-NC-ND 4.0 International license.

352 2016). Contrasting with such assumption, our results revealed that while transfers played a

353 key role on Alphaherpesvirinae evolution, they were uncommon among Beta- and

354 Gammaherpesvirinae. For these two subfamilies, intrahost speciations followed by losses

355 were abundant (Figure 2B), and may provide better explanations for the topological

356 disagreements between their phylogenies and those of their hosts.

357 Viral losses do not necessarily mean extinctions, as they may also indicate 358 undersampling or undiscovered viruses. Since the highest levels of losses were observed 359 for herpesviral genera with few sampled taxa (Figure 3), a hypothesis of undiscovered 360 viruses appears to be plausible, as the relative frequency of losses were to some extent 361 influenced by the number of sampled taxa. If extinctions are invoked to explain these 362 losses, some events linked to the evolution of the hosts can be ascribed as potential 363 causes of the elimination of viral clades, one of them being host extinction. Although each 364 mass extinction could have wiped out from $76 \%$ to $96 \%$ of the ancient species, most 365 extinctions along the Phanerozoic Eon were the result of minor events taking place in366 between mass extinctions (Raup 1993). Since the average duration of species is 367 estimated to be four Myr, with genera lasting for around 28 Myr (Raup 1993), symbiont 368 extinction may explain some of the losses inferred in the present study.

369 Apart from host populations being wiped out, leading to viral elimination, cataclysmic

370 events can also cause drastic decreases in host populations (Hesse and Buckling 2016), 371 which may promote bottleneck effects directly affecting viral adaptation to hosts, and 372 leading to viral extinctions. It occurs especially because bottlenecks can increase the 373 likelihood of fixation of certain host alleles, including those granting host resistance to 374 pathogens (Hesse and Buckling 2016). Among bird species, for example, a strong 375 bottleneck impacted avian populations after the $5^{\text {th }}$ mass extinction (Feduccia 2003), 376 decreasing by nearly half the net diversification rates of birds along the Paleocene and 
377 Eocene ( 66-45 Mya) (Claramunt and Cracraft 2015). Such decline in host diversity may

378 possibly explain some of the losses inferred in clades of avian HVs, especially those

379 belonging to Iltovirus (Figure 3 and Figure 4).

380 Since direct or indirect contact are required for viral spread into new hosts, the 381 geological movement of landmasses can split or merge host populations, in this way 382 allowing or preventing certain host switches (Lovisolo et al. 2003). For a better 383 understanding of ancestral host transfers, it is important to consider the biogeography 384 (spatial distribution) of ancestral hosts, and the geological history of the Earth. As shown at 385 the bottom of Figure 4, Figure 5 and Figure 6, alongside the evolution of hosts and their 386 associated viruses, the planet underwent drastic changes. All hosts included in this study 387 are tetrapods, a group of organisms that diverged from aquatic vertebrates between 385 388 and 375 Mya (George and Blieck 2011). Given that the most probable tMRCA of 389 herpesviruses dates from 416 and 373 Mya, ancestors of such viruses probably infected 390 marine organisms, and along their terrestrialization, their viruses diverged into ancestors of 391 the known Alpha-, Beta-, and GammaHVs. Being the first to diverge, AlphaHVs were 392 probably lost on synapsids (proto-mammals) in the Carboniferous, reappearing as 393 mammalian HVs much later, when avian AlphaHVs got transferred to mammals in at least 394 two independent events (Figure 4). Such transfers, which gave rise to Simplexvirus and 395 Varicellovirus, were already suggested in previous studies to explain the dispersal of HVs 396 in mammalian hosts (McGeoch and Gatherer 2005; McGeoch et al. 2006). Our previous 397 study has shown that HVs gained, duplicated and lost specific protein domains along their 398 evolutionary history (Brito and Pinney 2020). Before and after colonizing their new hosts, 399 simplexviruses acquired, duplicated and lost domains encoded mainly in envelope and 400 modulatory proteins, while varicelloviruses evolved by altering their repertoire of envelope 401 and auxiliary protein domains. 
Although parasites are more likely to jump between closely related hosts, as they

403 share similar ecological, physiological and chemical characteristics (de Vienne et al. 2013;

404 Geoghegan et al. 2017), host switches can also occur over great phylogenetic distances,

405 as hosts from closely related clades can independently acquire or lose immunogenetic

406 traits (epitopes, domains or whole genes), which may change their levels of susceptibility

407 to pathogens (Longdon et al. 2014). As host populations could have been not only

408 physically but also genetically closer in early times than they are in current times, the

409 origins of mammalian HVs by means of host transfers from avian ancestors could be a

410 reasonable explanation.

411 In our analysis, except for the two transfers discussed above, all host switches were

412 found in more recent times, especially after the Cretaceous/Paleogene boundary ( 66

413 Mya). This pattern was already expected, as pointed out in a previous study, which found

414 recent host switches as a predominant evolutionary patter in most DNA and RNA viruses

415 (Geoghegan et al. 2017). Our results revealed that host switches were more prominent

416 among simplexviruses. A remarkable example is the transfer involving FBaHV1 and

417 MaHV1, which are closely related to primate HVs, but infect distantly related hosts (bats of

418 the genus Pteropus and marsupials, respectively). As ancestors of Pteropus $s p$.

419 (Megabats) inhabited Eurasia alongside primate ancestors in the Paleocene and Eocene

420 ( 59-38 Mya) (Springer et al. 2011; Springer et al. 2012), transfers of HVs from primates

421 to bats were probably more likely to happen in that period. Finally, the subsequent host

422 switch from megabats to macropods (Kangaroo and Wallaby ancestors) can be mainly

423 explained by their current and ancestral distributions in Australia, and by the dispersal

424 capabilities of bats using powered flight (Springer et al. 2011). As our previous study

425 revealed, both FBaHV1 and MaHV1 underwent major genomic reshaping after being

426 transferred from primates and diverge into two viral species: FBaHV1 gained and 
427 duplicated a series of envelope and modulatory protein domains, while MaHV1 lost at 428 least eight domains, mainly present in envelope proteins (Brito and Pinney 2020). Given 429 the defensive and offensive strategies of evolution adopted by pathogens and their hosts 430 in molecular arms races (Daugherty and Malik 2012), herpesviruses likely succeeded at 431 host switching by evading and/or neutralizing host immune factors by acquiring and losing 432 elements from their domain repertoires (Brito and Pinney 2017; Brito and Pinney 2020). Host switches involving primate HVs were observed in all herpesvirus subfamilies, 434 most of them taking place after $\sim 10$ Mya, along the Miocene, Pliocene and Quaternary. 435 Wertheim and colleagues (Wertheim et al. 2014) performed an in-depth analysis of the 436 evolution of Human simplexviruses (HHV1 and HHV2) and suggested that HHV2 could 437 have originated from host switches of HVs from Chimpanzees around 1.6 Mya. Our 438 findings have confirmed this transfer, positioning it slightly earlier in time, around 2 Mya $439(95 \%$ HPD $=3.6-0.1$ Mya $)$, after the divergence of ChHV1 and HHV2. The same study 440 has also pointed out another possible host switch involving ancestors of CeHV2. Our 441 results revealed that simplexviruses infecting Old World Monkeys, such as CeHV1, 442 CeHV2, and CeHV16 (Figure 1), underwent host switches after 4.3 Mya. Remarkably, all 443 species of the genera Cercopithecus and Papio (except $P$. hamadryas) are found only in 444 Africa, while those of the Macaca genus are mostly found in Asia (except M. sylvanus) 445 (Springer et al. 2012). Ancestors of Macaca dispersed from Africa to Asia in the Pliocene, 446 between 5.4 and 2.3 Mya (Springer et al. 2012), a period that matches the tMRCA of 447 simplexviruses infecting Old World Monkeys. Thereby, our findings suggest that transfers 448 of HVs from Cercopithecus to Macaca took place before the migration of the latter to Asia, 449 which explains the presence of CeHV1 infecting M. Mulatta. Finally, between 3.5 and 0.07 450 Mya, transfers from Cercopithecus to ancestors of Papio took place in Africa, the place of 
451 origin and current area of distribution of most species from both genera (Springer et al.

452 2012).

It is known that herpesviral host switches occurred frequently in the past, especially

454 among closely related organisms (Thiry et al. 2006; Tischer and Osterrieder 2010). As

455 mutation rate and effective population size $(\mathrm{Ne})$ affect the likelihood of adaptation of a

456 pathogen in a new host (Longdon et al. 2014), the extinction of viruses transmitted to new

457 host species may occur frequently (Geoghegan et al. 2017). As a result, most host

458 switches cannot be easily detected, and the number of transfers inferred in our co-

459 phylogenetic analysis is probably underestimated.

460 In conclusion, in this study we used time-calibrated virus-host phylogenies to perform

461 tree reconciliations. By means of this approach we were not only able to detect topological

462 disagreements between viral and host tree topologies, but more importantly, we reveal major

463 chronological mismatches on divergence times of animal species and their herpesviruses,

464 showing the relevance and fundamental contribution of temporal data for reconciling

465 phylogenies. Our dated reconciliations highlighted the central roles of intrahost speciations in

466 the evolution of herpesviruses, events that in most cases were followed by losses, which were

467 predominant along the Cretaceous period. It was not possible to clarify what such losses

468 represent in the evolution of herpesviruses, as they can represent lineage sorting events,

469 undiscovered viruses, or even episodes of viral extinctions. As more viral samples are

470 incorporated in tree reconciliations, the real nature of such losses will be revealed. Host

471 switches were particularly frequent among alphaherpesviruses, especially those of the genus

472 Simplexvirus. Viruses from this genus and other genera deserve further studies to uncover

473 whether the gain or loss of specific genetic traits (domains and genes) may have favoured the

474 colonization of new hosts or tissues (Brito and Pinney 2020). Finally, contrasting what was 
475 previously thought, cospeciations between herpesviruses and their hosts are rare events,

476 mainly observed among alphaherpesviruses.

\section{MATERIALS AND METHODS}

480 Host/virus species and phylogenetic analysis

481 A total of 72 herpesviruses (subfamilies Alpha-, Beta-, and Gammaherpesvirinae)

482 and their 37 host species (mammals, birds and reptiles) were included in this study (see

483 S1 Table). Only viral species with whole genomes available on NCBI Viral Genomes

484 Resource (Brister et al. 2015) were considered in the analysis. To infer both host and viral

485 species phylogeny, sequences of host nuclear genes and conserved viral proteins were

486 retrieved from NCBI. Sequence of genes encoding BDNF, CNR1, EDG1, RAG1, and RHO

487 were used for inferring the host tree, and the viral tree was generated using sequences of

488 orthologs of the HHV1 genes UL15, UL27 and UL30 (McGeoch et al. 2000). For host

489 genes, when species-specific sequences were not available, sequences from related

490 species from the same taxonomic group were used. Each gene set was aligned using

491 MAFFT (Katoh and Standley 2013), and models of nucleotide and amino acid substitution

492 were determined using jModelTest (Posada 2008) and ProtTest (Darriba et al. 2011),

493 respectively. The multiple sequence alignments were used as partitions in *BEAST to infer

494 maximum clade credibility (MCC) species trees using the Markov Chain Monte Carlo

495 (MCMC) Bayesian approach implemented in BEAST v2.4.5 (Bouckaert et al. 2014). The

496 analyses were performed using relaxed (uncorrelated lognormal) molecular clock, with the

497 Yule model as a coalescent prior. The host tree was run for 500 million generations, and

498 the viral one for 35 million generations. 
The host tree had their node ages time-calibrated (in Millions of years, Myr) using as

500 priors host divergence dates obtained from (Hedges and Kumar 2009; dos Reis et al.

501 2012; Claramunt and Cracraft 2015). With that, all internal nodes in the host phylogeny

502 were assigned with lower and upper bounds for divergence times, which match the

503 divergence dates provided at timetree.org (Kumar et al. 2017). Since fossil records or

504 other ancestral evidences are not available for herpesviruses, viral divergence times were

505 calibrated using theoretical estimates derived from molecular clock analyses performed by

506 (McGeoch and Gatherer 2005; Wertheim et al. 2014). Following the same strategy used

507 by (Brito and Pinney 2020), in the herpesvirus phylogeny, only the deepest node (root)

508 and a shallow internal node representing the divergence between HHV1-HHV2 were

509 assigned with time calibration priors, while the remaining nodes were left free to have had

510 their divergence times inferred from sequence data. Constraints of monophyly were

511 applied for viral clades based on the current taxonomic classification provided by ICTV

512 (King et al. 2018), and host clades were constrained according to two recent and

513 comprehensive studies (dos Reis et al. 2012; Claramunt and Cracraft 2015). Such

514 constraints allowed the reconstruction of robust phylogenies, which fully agree with the

515 current taxonomy of viral and host groups under study.

517 Tree reconciliation

518 Tree reconciliations were performed separately for each HV subfamily using the

519 program Jane 4 (Conow et al. 2010). Such analyses were performed to find low cost

520 associations between host and viral trees, while keeping their original topologies. Taking

521 advantage of their node height highest posterior density (HPD) intervals, all trees were

522 converted into a Jane timed tree format using a Python script available at GitHub (see

523 Data Availability). At this step, the continuous time scales of the phylogenies were 
524 discretized into bins of 5 Myrs ("time zones") shared by viral and host trees. In this way,

525 the internal nodes of host and viral trees could be assigned to specific time frames,

526 ensuring that only nodes belonging to the same time zone could be associated for inferring

527 potential host switches and cospeciation events, thus avoiding chronological

528 inconsistencies. The algorithm implemented in Jane allows internal nodes to be assigned

529 to more the one time zone, and requires that all zones should be populated with at least

530 one host node. To meet such requirement, an outgroup clade containing artificial taxa was

531 added to the original host tree, ensuring that their internal nodes could span time zones

532 not originally covered by the original host nodes. A similar outgroup was added to the viral

533 tree, allowing the pairing of artificial virus-host pairs.

534 Since it is not possible to ascertain the actual relative costs of events of

535 cospeciations, intrahost speciation, host switches or losses in the evolution of HVs, we

536 reconciled trees under multiple combinations of relative costs, in which those events were

537 weighted with cost values varying from 0 to 3 . For each HV subfamily, a total of 256 co-

538 phylogenetic cost regimes were explored, generating several solutions, which differed in

539 terms of overall cost and number of inferred events (see supplementary tables S2-S4). In

540 this solution space, the median number of inferred events for each event type was

541 calculated, and an optimal cost regime was selected based on its ability to: (i) produce the

542 exact or similar reconciliation scenario with total number of inferred events equivalent to

543 the median values, (ii) in which events have the highest possible supporting values, (iii)

544 with the lowest overall cost. Following these criteria, the selected cost regime had the

545 following relative costs of events: $\operatorname{cospeciations~}=0$; intrahost speciation $=1$; host switches

$546=2 ;$ and losses $=0$ (see supplementary tables S2-S4). 


\section{ACKNOWLEDGEMENTS}

550 AFB is funded by Ciência sem Fronteiras, a scholarship programme managed by the

551 Brazilian federal government (CAPES, Ministry of Education, Grant number: 11911-13-1).

552 JWP is supported by a University Research Fellowship from the Royal Society. The

553 authors thank the Imperial College London Open Access Fund for the financial support.

\section{DATA AVAILABILITY}

556 All genome used mentioned in this study have their accession numbers listed as

557 Supplementary Data. All data and codes generated in this study are deposited in the

558 following repository on GitHub:

559 https://github.com/andersonbrito/openData/tree/master/brito 2020 reconciliation.

\section{SUPPLEMENTARY DATA}

562 Supplementary Materials are available online. Supplementary Table S1 shows the list of

563 genomes used in this study. Supplementary Tables S2-4 lists all cost regimes used for

564 inferring possible scenarios explaining the evolution of Alpha-, Beta, and

565 Gammaherpesviruses.

\section{COMPETING INTERESTS}

568 The authors declare that they have no competing interests.

\section{REFERENCES}

572 Baker ML, Jiang W, Rixon FJ, Chiu W. 2005. Common ancestry of herpesviruses and tailed DNA bacteriophages. Journal of virology 79: 14967-14970. 
Blewett EL, Sherrod CJ, Texier JR, Conrad TM, Dittmer DP. 2015. Complete Genome Sequences of Mandrillus leucophaeus and Papio ursinus Cytomegaloviruses. Genome announcements 3.

Bouckaert R, Heled J, Kuhnert D, Vaughan T, Wu CH, Xie D, Suchard MA, Rambaut A, Drummond AJ. 2014. BEAST 2: a software platform for Bayesian evolutionary analysis. PLoS computational biology 10: e1003537.

Brister JR, Ako-Adjei D, Bao Y, Blinkova O. 2015. NCBI viral genomes resource. Nucleic acids research 43: D571-577.

Brito AF, Pinney JW. 2017. Protein-Protein Interactions in Virus-Host Systems. Frontiers in microbiology 8: 1557.

Brito AF, Pinney JW. 2020. The evolution of protein domain repertoires: Shedding light on the origins of the Herpesviridae family. Virus Evol 6: veaa001.

Claramunt S, Cracraft J. 2015. A new time tree reveals Earth history's imprint on the evolution of modern birds. Science advances 1: e1501005.

Conow C, Fielder D, Ovadia Y, Libeskind-Hadas R. 2010. Jane: a new tool for the cophylogeny reconstruction problem. Algorithms for molecular biology : AMB 5: 16.

Darriba D, Taboada GL, Doallo R, Posada D. 2011. ProtTest 3: fast selection of best-fit models of protein evolution. Bioinformatics 27: 1164-1165.

Daugherty MD, Malik HS. 2012. Rules of engagement: molecular insights from host-virus arms races. Annual review of genetics 46: 677-700.

Davison AJ. 2002. Evolution of the herpesviruses. Veterinary microbiology 86: 69-88.

Davison AJ. 2010. Herpesvirus systematics. Veterinary microbiology 143: 52-69.

Davison AJ, Eberle R, Ehlers B, Hayward GS, McGeoch DJ, Minson AC, Pellett PE, Roizman B, Studdert MJ, Thiry E. 2009. The order Herpesvirales. Archives of virology 154: 171-177. 
de Vienne DM, Refregier G, Lopez-Villavicencio M, Tellier A, Hood ME, Giraud T. 2013. Cospeciation vs host-shift speciation: methods for testing, evidence from natural associations and relation to coevolution. The New phytologist 198: 347-385.

dos Reis M, Inoue J, Hasegawa M, Asher RJ, Donoghue PC, Yang Z. 2012. Phylogenomic datasets provide both precision and accuracy in estimating the timescale of placental mammal phylogeny. Proceedings Biological sciences 279: 3491-3500.

Ehlers B, Dural G, Yasmum N, Lembo T, de Thoisy B, Ryser-Degiorgis MP, Ulrich RG, McGeoch DJ. 2008. Novel mammalian herpesviruses and lineages within the Gammaherpesvirinae: cospeciation and interspecies transfer. Journal of virology $\mathbf{8 2}$ : 3509-3516.

Escalera-Zamudio M, Rojas-Anaya E, Kolokotronis SO, Taboada B, Loza-Rubio E, Mendez-Ojeda ML, Arias CF, Osterrieder N, Greenwood AD. 2016. Bats, Primates, and the Evolutionary Origins and Diversification of Mammalian Gammaherpesviruses. mBio 7.

Feduccia A. 2003. 'Big bang' for tertiary birds? Trends in Ecology \& Evolution 18: 172-176.

Geoghegan JL, Duchene S, Holmes EC. 2017. Comparative analysis estimates the relative frequencies of co-divergence and cross-species transmission within viral families. PLoS pathogens 13: e1006215.

George D, Blieck A. 2011. Rise of the earliest tetrapods: an early Devonian origin from marine environment. PloS one 6: e22136.

Gradstein FM, Ogg JG, Schmitz M, Ogg G. 2012. The Geologic Time Scale 2012. Elsevier, The Amsterdam.

Hedges SB, Kumar K. 2009. The Timetree of Life. Oxford University Press, New York.

Hesse E, Buckling A. 2016. Host population bottlenecks drive parasite extinction during antagonistic coevolution. Evolution; international journal of organic evolution $\mathbf{7 0 :}$ 235-240.

Jackson A. 2005. The effect of paralogous lineages on the application of reconciliation analysis by cophylogeny mapping. Systematic biology 54: 127-145. 
bioRxiv preprint doi: https://doi.org/10.1101/418111; this version posted May 17,2020 . The copyright holder for this preprint (which was

not certified by peer review) is the author/funder, who has granted bioRxiv a license to display the preprint in perpetuity. It is made available under aCC-BY-NC-ND 4.0 International license.

646 McGeoch DJ, Dolan A, Ralph AC. 2000. Toward a comprehensive phylogeny for

648 McGeoch DJ, Gatherer D. 2005. Integrating reptilian herpesviruses into the family

Johnson KP, Adams RJ, Page RD, Clayton DH. 2003. When do parasites fail to speciate in response to host speciation? Systematic biology 52: 37-47.

Katoh K, Standley DM. 2013. MAFFT multiple sequence alignment software version 7: improvements in performance and usability. Molecular biology and evolution 30: 772-780.

King AMQ, Lefkowitz EJ, Mushegian AR, Adams MJ, Dutilh BE, Gorbalenya AE, Harrach B, Harrison RL, Junglen S, Knowles NJ et al. 2018. Changes to taxonomy and the International Code of Virus Classification and Nomenclature ratified by the International Committee on Taxonomy of Viruses (2018). Archives of virology doi:10.1007/s00705-018-3847-1.

Kumar S, Stecher G, Suleski M, Hedges SB. 2017. TimeTree: A Resource for Timelines, Timetrees, and Divergence Times. Molecular biology and evolution 34: 1812-1819.

Longdon B, Brockhurst MA, Russell CA, Welch JJ, Jiggins FM. 2014. The evolution and genetics of virus host shifts. PLoS pathogens 10: e1004395.

Lovisolo O, Hull R, Rosler O. 2003. Coevolution of viruses with hosts and vectors and possible paleontology. Advances in virus research 62: 325-379.

McGeoch DJ, Cook S, Dolan A, Jamieson FE, Telford EA. 1995. Molecular phylogeny and evolutionary timescale for the family of mammalian herpesviruses. Journal of molecular biology 247: 443-458.

mammalian and avian herpesviruses. Journal of virology 74: 10401-10406.

$$
\text { herpesviridae. Journal of virology 79: 725-731. }
$$

McGeoch DJ, Rixon FJ, Davison AJ. 2006. Topics in herpesvirus genomics and evolution. Virus research 117: 90-104.

Page RDM, Charleston MA. 1998. Trees within trees: phylogeny and historical associations. Trends in Ecology \& Evolution 13: 356-359. 
Peters SE, McClennen M. 2015. The Paleobiology Database application programming interface. Paleobiology 42: 1-7.

Posada D. 2008. jModelTest: phylogenetic model averaging. Molecular biology and evolution 25: 1253-1256.

Raup DM. 1993. Extinction from a paleontological perspective. European review 1: 207216.

Springer MS, Meredith RW, Gatesy J, Emerling CA, Park J, Rabosky DL, Stadler T, Steiner C, Ryder OA, Janecka JE et al. 2012. Macroevolutionary dynamics and historical biogeography of primate diversification inferred from a species supermatrix. PloS one 7: e49521.

Springer MS, Meredith RW, Janecka JE, Murphy WJ. 2011. The historical biogeography of Mammalia. Philosophical transactions of the Royal Society of London Series B, Biological sciences 366: 2478-2502.

Thiry J, Keuser V, Muylkens B, Meurens F, Gogev S, Vanderplasschen A, Thiry E. 2006. Ruminant alphaherpesviruses related to bovine herpesvirus 1. Veterinary research 37: 169-190.

Tischer BK, Osterrieder N. 2010. Herpesviruses--a zoonotic threat? Veterinary microbiology 140: 266-270.

Wertheim JO, Smith MD, Smith DM, Scheffler K, Kosakovsky Pond SL. 2014. Evolutionary origins of human herpes simplex viruses 1 and 2. Molecular biology and evolution 31: 2356-2364. 
bioRxiv preprint doi: https://doi.org/10.1101/418111; this version posted May 17,2020 . The copyright holder for this preprint (which was

not certified by peer review) is the author/funder, who has granted bioRxiv a license to display the preprint in perpetuity. It is made available under aCC-BY-NC-ND 4.0 International license.

\section{FIGURES}

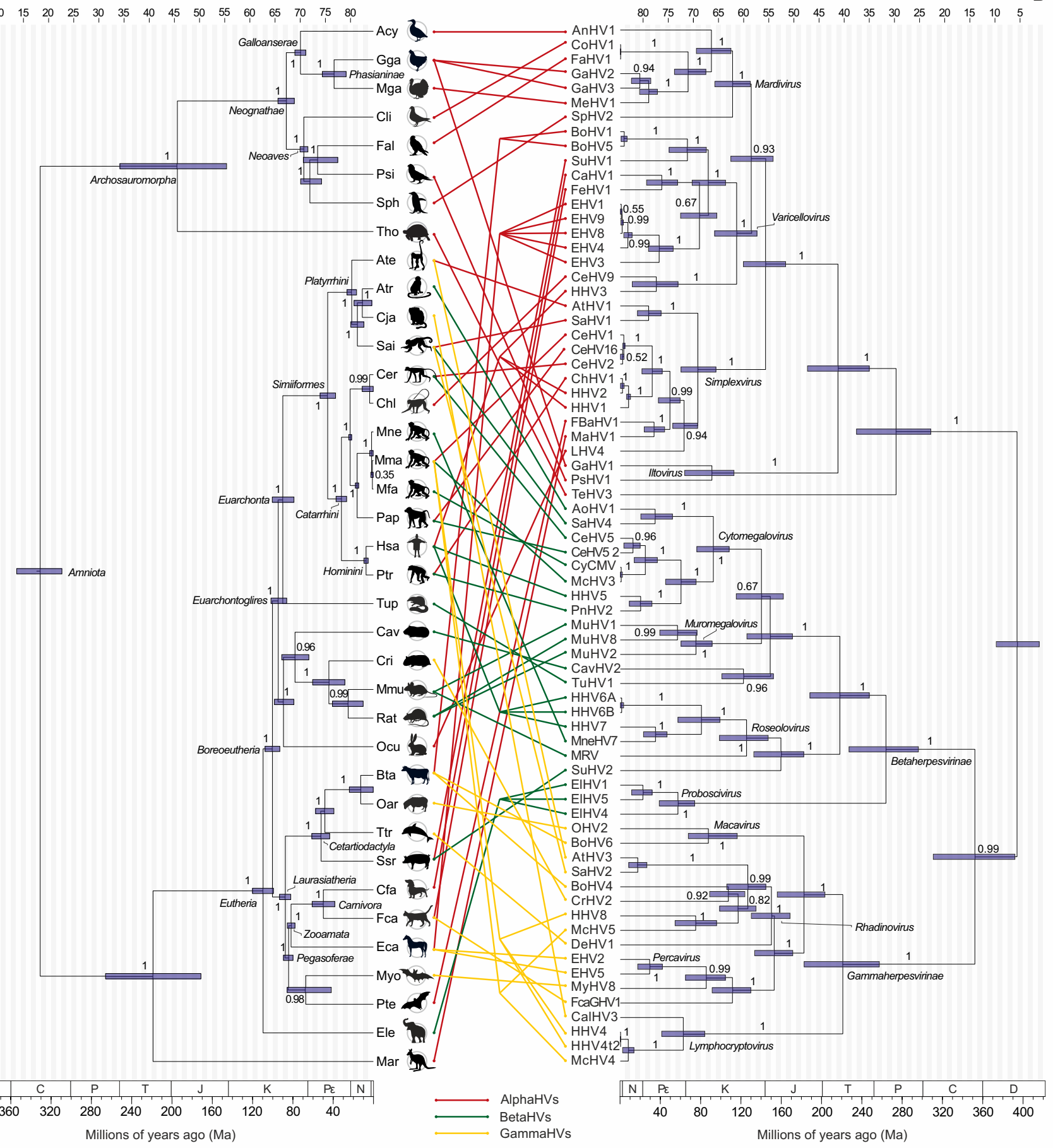


A

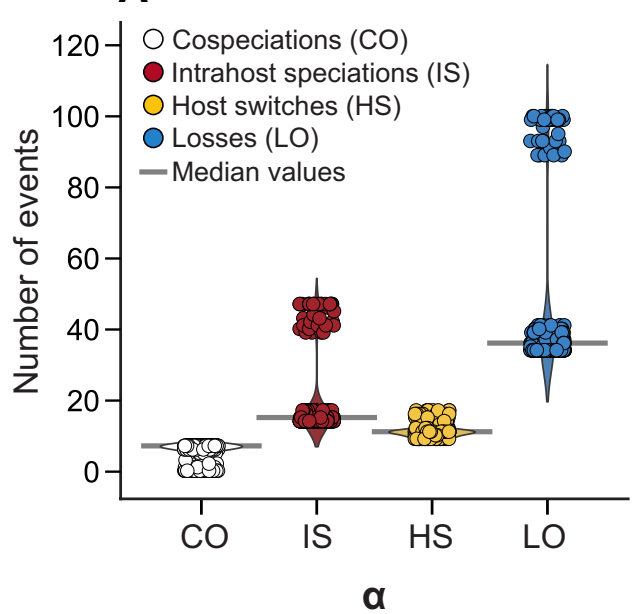

B

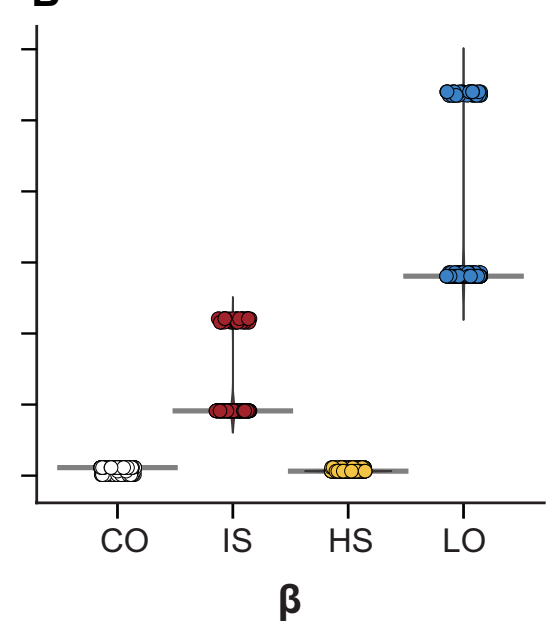

C

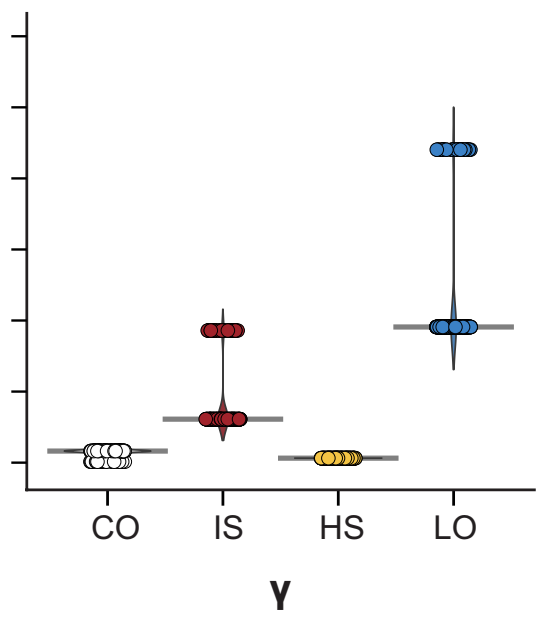




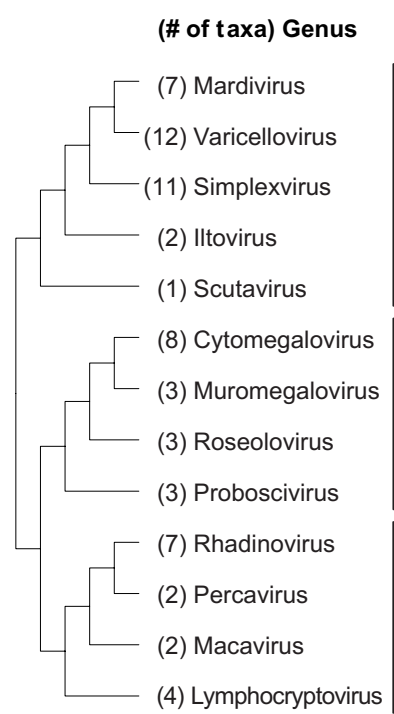

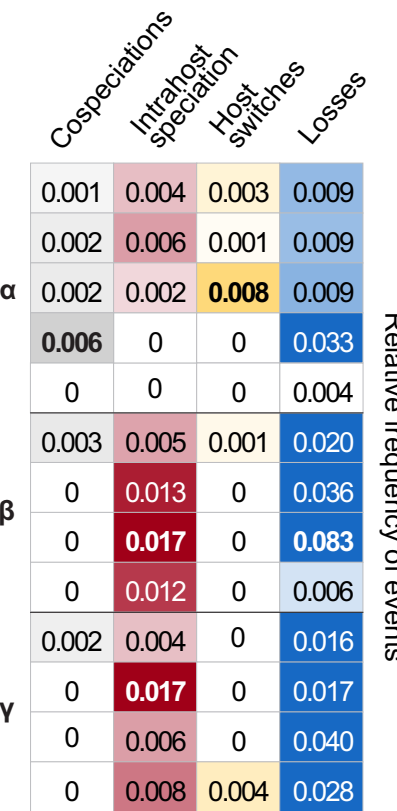


bioRxiv preprint doi: https://doi.org/10.1101/418111; this version posted May 17,2020 . The copyright holder for this preprint (which was

not certified by peer review) is the author/funder, who has granted bioRxiv a license to display the preprint in perpetuity. It is made available under aCC-BY-NC-ND 4.0 International license.

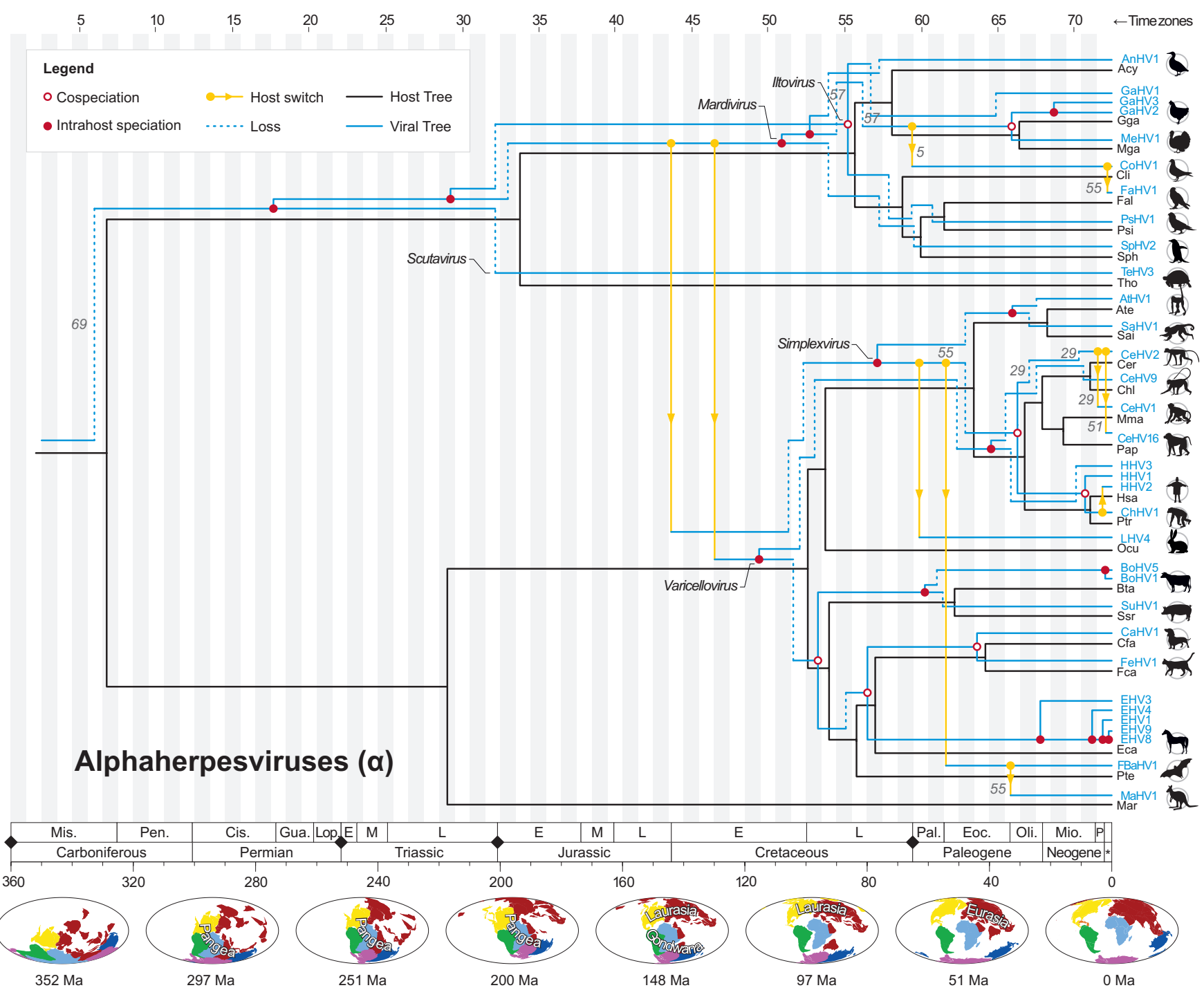


bioRxiv preprint doi: https://doi.org/10.1101/418111; this version posted May 17,2020 . The copyright holder for this preprint (which was

not certified by peer review) is the author/funder, who has granted bioRxiv a license to display the preprint in perpetuity. It is made available under aCC-BY-NC-ND 4.0 International license.

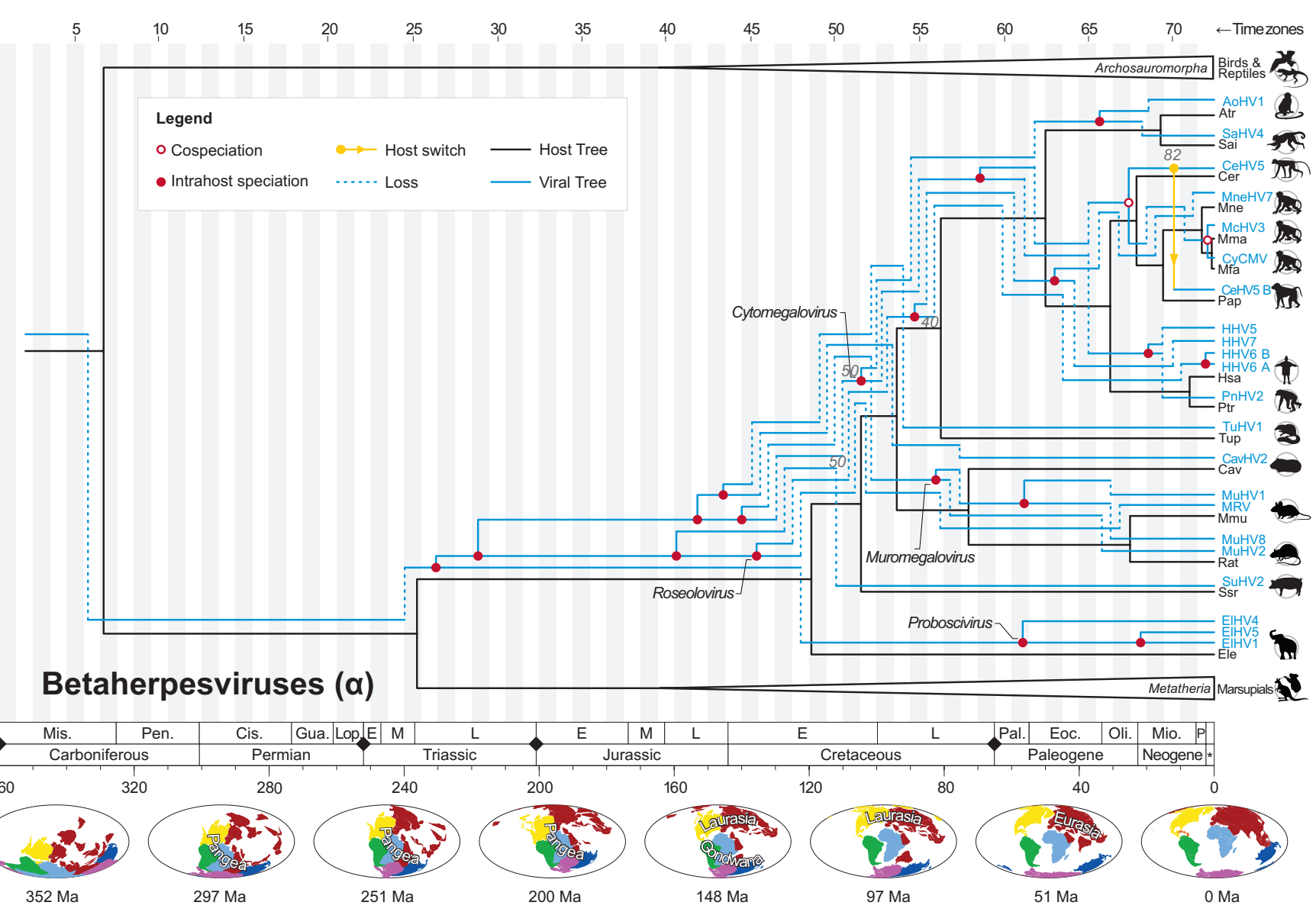

Figure 5 
bioRxiv preprint doi: https://doi.org/10.1101/418111; this version posted May 17,2020 . The copyright holder for this preprint (which was

not certified by peer review) is the author/funder, who has granted bioRxiv a license to display the preprint in perpetuity. It is made available under aCC-BY-NC-ND 4.0 International license.

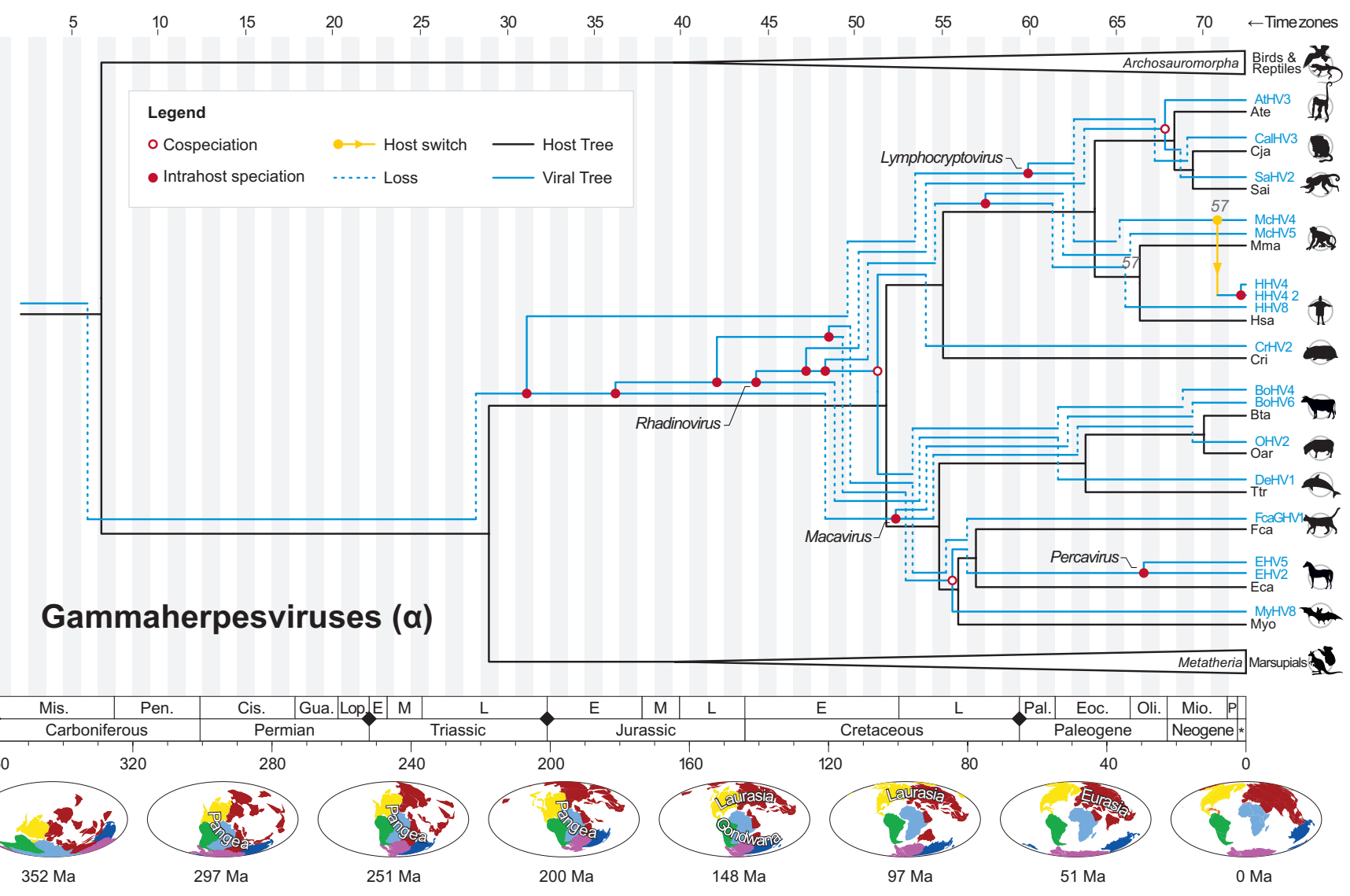

